\title{
POSTERIOR PERIPHERAL (ECCENTRIC) LENTICONUS* WITH A NOTE ON THE EVOLUTION OF LENTICONI
}

BY

\author{
K. NATH AND B. R. SHUKLA \\ Muslim University Institute of Ophthalmology, Aligarh, India
}

POSTERIOR lenticonus is a rare congenital anomaly first described by Meyer (1888), about a hundred cases having since been reported. Posterior eccentric lenticonus is rarer. In the literature available to the authors, only two other cases with any resemblance to the present case were found. The first example of this anomaly was fully reported by Franceschetti and Rickli (1954), and Lisch (1956) found peripheral posterior lenticonus in a patient with microphakia.

\section{Case Report}

A boy aged 10 years was referred to the Gandhi Eye Hospital, Aligarh, on October 11, 1962, complaining of a gradual diminution of vision in the left eye for 4 months. The patient was the third child and there was no history of birth injury or of maternal illness during pregnancy. The boy's mother had noticed impairment of vision in the left eye in 1951 at the age of 17 and a cataract had been removed in 1958 at the age of 25. There was no history of trauma in her case, but she was not available for examination. Nothing else was significant in the family history.

Examination.-The child was well built and quite intelligent, with no bodily defects. The posterior part of the lens was slightly hazy. Slit-lamp examination with undilated pupils showed no other abnormality. Dilatation of the pupils revealed an incomplete bubble-like appearance in the lower part due to ectasia of the lens below; slit-lamp examination disclosed a peripheral eccentric lenticonus, the upper margin of the ectasia being sharply defined and about $2 \mathrm{~mm}$. below the posterior pole (Fig. 1, opposite).

The lower margin was not defined at all and the ectasia extended almost to the periphery of the lens (Fig. 2, opposite).

The ectatic portion was also slightly displaced towards the nasal side. The upper and temporal margins were sharply defined, i.e. there was a sudden change in curvature at these points. The nasal margin was sloping and ill-defined, and there was a thick ring-shaped lenticular opacity adjacent to it below the posterior capsule.

About three-quarters of the posterior lens capsule and its subcapsular cortex showed scattered irregular lenticular changes. The embryonic and foetal nuclei were normal. Y-sutures were normal. No abnormality of the thickness of the capsule could be assessed because of the lens changes. There were no remnants of hyaloid or of the tunica vasculosa lentis. The visible part of the anterior vitreous was normal.

The right eye showed no abnormality, and the fundus was normal in both eyes.

The visual acuity in the right eye was $6 / 6$ and in left eye 6/18. The refraction in the right eye was $+1 \mathrm{D}$ sph., and in the left eye $+2.5 \mathrm{D}$ sph., $+0.5 \mathrm{D}$ cyl., axis $180^{\circ}$, and could not be improved beyond 6/12 partly. 


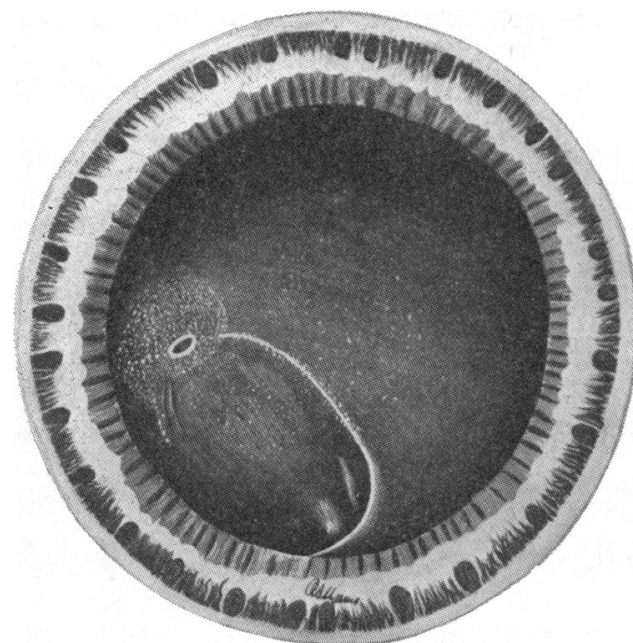

FIG. 1.-Drawing of peripheral lenticonus in left eye. Note the upper and outer sharp boundaries, and the ring-shaped opacity adjacent to the sloping nasal margins. The ectasia extends below towards the periphery.

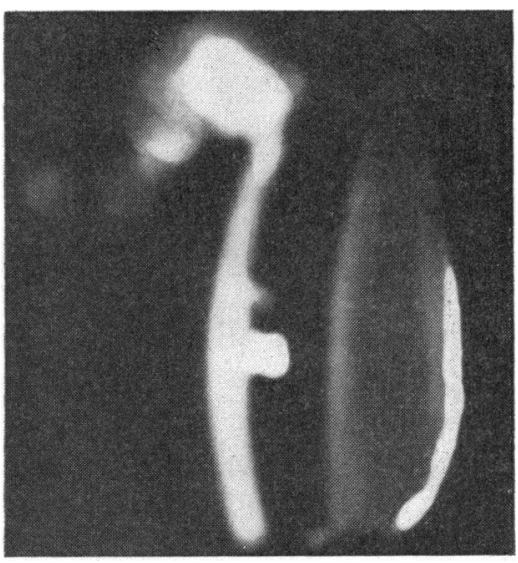

FIG. 2.-Slit-lamp photograph of peripheral (eccentric) posterior lenticonus. Note increased thickness of lens cortex in the lower part, and the extension of the ectasia almost to the periphery.

\section{Comment}

This case showed several atypical features, the pathogenesis of which can only be surmised. The ectasia was confined to the lower part of the posterior capsule extending almost to the periphery, and there were no remnants of hyaloid or of the tunica vasculosa lentis. The embryonic and infantile nuclei were normal. There was no collar-stud opacity in the lens as is often seen in cases of lenticonus (Tyson, 1928). On the other hand, there was a thick ring-shaped posterior subcapsular cortical opacity, situated close to the sloping nasal margins of the conus. Another point of interest is the history of early cataract in the mother. The affected eye had good vision which had only recently started to diminish, and there was no squint.

The cause and the exact time of onset of this condition are not clear, and it is not known whether it is congenital or acquired. It may start late in intra-uterine life or soon after birth. The main cause appears to be inherent weakness in the lens capsule and the conus may develop very slowly. The progress of the lenticonus was observed by Franceschetti and Rickli (1954) and Rosen (1945) watched a case which developed into lenticonus after trauma.

Most of the causes elaborated by Marsh (1932) can be ruled out in the present case, but Marsh also suggested that the defect might result from accommodative strain on the highly plastic lens of a young child.

Franceschetti and Rickli (1954) and Makley (1955) examined cases of posterior lenticonus histopathologically and found lens epithelium in the region of ectasia. It is suggested that the unusually increased convexity of 
the lens capsule (which exists normally in the equatorial region) may stimulate the multiplication of the cells of the anterior subcapsular epithelium or the epithelial remnants under the posterior capsule, and may also encourage the laying down of new lens fibres which normally occurs in the equatorial region. It thus appears that the primary defect may be a deficiency of the zonular lamella.

If these fibres are laid down at a particular place, all stages of abnormality are to be expected. If these epithelial cells start growing where they are not supposed to be present, a gradual increase in ectasia will occur. The usual site is the region of the poles but the anomaly may occur anywhere except in the true equatorial region where the growth gives rise to a normal moulding of lens fibres, resulting in a lens of normal shape.

It is, therefore, further suggested that there may be some common link between lentiglobus, lenticonus, and the development of the zonular lamella of the lens capsule, which develops late in intra-uterine life. The zonular lamella starts to develop from the equatorial region of the globe and finally reaches the polar regions. The zonular lamella may remain thin at certain places, particularly at the polar regions where it develops last, and when it is deficient near the polar regions the development of anterior or posterior lenticonus may be stimulated by the stress and strain of accommodation. When, however, the deficiency of the zonular lamella is generalized there is a tendency towards the development of lentiglobus.

The pathogenesis of this anomaly may therefore be summarized as follows. The primary defect lies in the capsule of the lens, where the zonular lamella may be deficient. Under the stress and strain of accommodation, the capsule starts to give way and the curvature increases. This stimulates the capsule of the equatorial region and this in turn stimulates the cells of the anterior lens epithelium or the remnants of epithelium under the posterior lens capsule, so that new lens fibres and epithelial cells are laid down irregularly. This laying down of new lens fibres beneath the weak capsule causes a conical protruberance of the already curved lens capsule and thus lenticonus is formed. When the change in the capsule is sudden we find a sharp margin of lenticonus, whereas a sloping margin is formed by a gradual transition from the deficient to the normal capsule. A thinning of the capsule was noted by Makley (1955).

Since the mother of this patient had a lenticular opacity at the age of 18 , the possibility of a hereditary factor cannot be ruled out; the familial incidence of lenticonus was noticed by Harrison Butler (1930) and Luo (1935).

\section{Conclusion}

No definite cause of the peripheral (eccentric) lenticonus in the present case can be given. Lenticonus and lentiglobus may arise from an inherent 
weakness of the lens capsule, with a deficient or absent zonular lamella. A localized deficiency would give rise to lenticonus, which occurs more often in the polar region. Here the zonular lamella develops late and the deficiency may cause increased curvature of the capsule; this may stimulate the quiescent epithelial cells of the lens and the anomaly may progress under the stress and strain of accommodation.

\section{REFERENCES}

Butler, T. Harrison. (1930). Arch. Ophthal. (Chicago), 3, 425.

FrANSCESCHETTI, A., and RiCKLI, H. (1954). A.M.A. Arch. Ophthal., 1, 499.

LisCH, K. (1956). v. Graefes Arch. Ophthal., 157, 287.

LUO, T. H. (1935). Brit. J. Ophthal., 19, 210.

MaKLeY, T. A. (1955). Amer. J. Ophthal. 39, 308.

MARSH, J. (1932). Arch. Ophthal. (Chicago), 8, 804.

MeYer, E. (1888). Z Zbl. Augenheilk., 12, 41.

Rosen, E. (1945). Brit. J. Ophthal., 29, 370.

Tyson, H. H. (1928). Arch. Ophthal. (N.Y.), 57, 38. 